\title{
Imaging Carotid Atherosclerosis Plaque Ulceration: Comparison of Advanced Imaging Modalities and Recent Developments
}

\author{
(D). Yuan, (D)A. Usman, (D). Das, (D)A.J. Patterson, (D).H. Gillard, and (D) M.J. Graves
}

\begin{abstract}
SUMMARY: Atherosclerosis remains the leading cause of long-term mortality and morbidity worldwide, despite remarkable advancement in its management. Vulnerable atherosclerotic plaques are principally responsible for thromboembolic events in various arterial territories such as carotid, coronary, and lower limb vessels. Carotid plaque ulceration is one of the key features associated with plaque vulnerability and is considered a notable indicator of previous plaque rupture and possible future cerebrovascular events. Multiple imaging modalities have been used to assess the degree of carotid plaque ulceration for diagnostic and research purposes. Early diagnosis and management of carotid artery disease could prevent further cerebrovascular events. In this review, we highlight the merits and limitations of various imaging techniques for identifying plaque ulceration.
\end{abstract}

ABBREVIATIONS: $C E-M R A=$ contrast-enhanced MRA; CDUS = color Doppler ultrasound; $C E U S=$ contrast-enhanced ultrasound; US = ultrasound; $\mathrm{XRA}=\mathrm{x}$-ray contrast angiography

$\mathbf{S}$ troke is considered the leading cause of death and long-term disability worldwide. ${ }^{1}$ Carotid atherosclerosis is one of the major causes of ischemic stroke. ${ }^{2}$ Morphologic features such as plaque ulceration are strongly correlated with ischemic stroke and coronary events, with hazard ratio ranges from 1.2 to $7.7,,^{3-8}$ as summarized in Table 1 . The hazard ratio is comparable with other high-risk factors such as large lipid core (hazard ratio $=1.75)$ and intraplaque hemorrhage (hazard ratio $=5.85$ ). ${ }^{9}$

Carotid plaque ulceration or surface irregularity is characterized as an indentation, fissure, or erosion on the luminal surface of a plaque, exposing a portion of the inner plaque to direct contact with the circulating blood. ${ }^{10}$ Various factors are involved in the pathogenesis of ulceration, including the accumulation of inflammatory cells, proteolytic enzymes released by macrophages, and local hemodynamic factors. ${ }^{11}$ These factors weaken the fibrotic cap, leading to plaque rupture and leaving behind the ulceration. These ulcerations act as a thromboembolic source, allowing plaque components to be released into the blood.

From the Department of Radiology (J.Y., A.U., J.H.G., M.J.G.), University of Cambridge, Cambridge, UK; and Department of Radiology (T.D., A.J.P., M.J.G.), Cambridge University Hospitals National Health Service Foundation Trust, Cambridge, UK.

Please address correspondence to Jianmin Yuan, Department of Radiology, School of Clinical Medicine, University of Cambridge, Level 5, Box 218, Addenbrooke's Hospital, Hills Rd, Cambridge, CB2 0QQ, UK; e-mail: jmyuan5@gmail.com

-- Indicates open access to non-subscribers at www.ajnr.org

三 Indicates article with supplemental on-line table.

http://dx.doi.org/10.3174/ajnr.A5026
Ulcerated plaques are considered the main foci of cerebral microemboli. ${ }^{12}$

Plaque ulceration can be visualized grossly following carotid endarterectomy and later by histologic analysis of the specimen. Figure 1 shows histologic images of an ulcerated plaque. ${ }^{13}$ Early detection of plaque ulceration before an operation is essential because it may assist in preventing further thromboembolic events; therefore, there has been substantial research to evaluate different radiographic techniques in the early identification of plaque ulceration.

Various imaging modalities are used to assess plaque ulceration for diagnostic and research purposes (Table 2 and On-line Table). These include $\mathrm{x}$-ray contrast angiography (XRA), B-mode and Doppler sonography, CTA, and MRA. The purpose of this article was to compare the different clinical imaging modalities in observing carotid ulceration from existing literature and evaluate the diagnostic value of each method.

\section{X-Ray Contrast Angiography}

$\mathrm{X}$-ray contrast angiography, including conventional carotid angiography or DSA, is an established method of assessing carotid artery disease. Conventional angiography involves the acquisition of digital fluoroscopic images in combination with the administration of an iodinated contrast medium. DSA produces the angiography by subtracting the postcontrast images from precontrast images to achieve better visualization of the blood vessels. Previously, XRA was considered a criterion standard for the assessment of carotid artery disease because of its high spatial (50 
Table 1: Summary of the hazard ratios of carotid ulceration for future events risk in different studies

\begin{tabular}{|c|c|c|c|c|}
\hline Studies & $\begin{array}{c}\text { Study } \\
\text { Population }\end{array}$ & Cardiovascular Events & Hazard Ratios $(95 \% \mathrm{Cl})$ & $P$ Value \\
\hline Eliasziw et al, $1994^{3}$ & 659 & Ipsilateral stroke at $24 \mathrm{mo}$ & $24(0.61-52) ; 43(49-7.88)$ & - \\
\hline Handa et al, $1995^{4}$ & 214 & Stroke events, average duration of $16 \mathrm{mo}$ & $7.68(15-27.40)$ & .002 \\
\hline Rothwell et al, $2000^{5}$ & 3007 & Previous myocardial infarction & $82(23-64)$ & $<.001$ \\
\hline Rothwell et al, $2000^{5}$ & 3007 & Nonstroke vascular death & $67(15-44)$ & .007 \\
\hline Rothwell et al, $2000^{6}$ & 3007 & Strokes occurring after 2 years & $75(30-80)$ & .01 \\
\hline Rothwell et al, $2000^{6}$ & 3007 & Ipsilateral ischemic stroke & $80(14-83)$ & .01 \\
\hline Rothwell et al, $2005^{8}$ & 1130 & 5-Year risk of ipsilateral ischemic stroke & $03(31-14)$ & .002 \\
\hline Prabhakaran et al, $2006^{7}$ & 1939 & Ischemic strokes during a mean follow-up of $6.2 \mathrm{yr}$ & $1(1-8.5)$ & - \\
\hline
\end{tabular}

Note:-- indicates not reported.
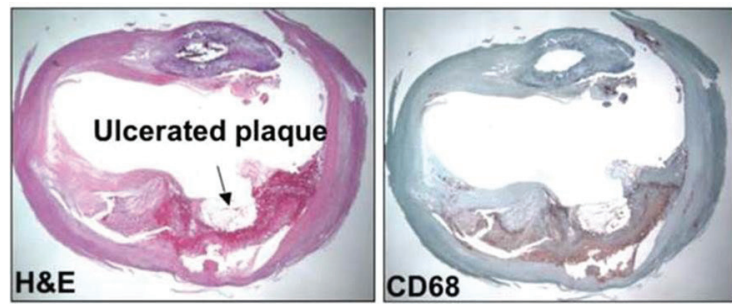

CD68

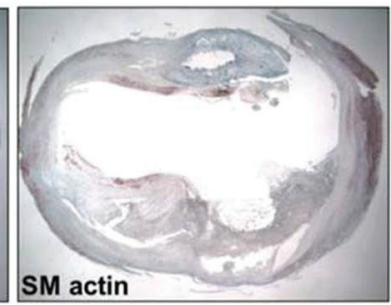

SM actin

FIG 1. Histologic section of an ulcerated plaque by using a hematoxylin-eosin stain showing the ulceration (left). The CD68 stain shows macrophages (middle), and the smooth-muscle actin stain shows a lack of smooth-muscle cells (right). Reprinted with permission from Gillard et al. ${ }^{13}$ Copyright Cambridge University Press 2007.

$\mu \mathrm{m})$ and temporal resolution (10 ms). It has the ability to depict the stenotic lumen and various plaque characteristics such as surface irregularities or large ulcerations. It has the advantage of visualizing a long segment of the artery at a single time point.

XRA has been widely used in large, randomized clinical trials, such as the North American Symptomatic Carotid Endarterectomy Trial (NASCET), ${ }^{14}$ the European Carotid Surgery Trial (ECST), ${ }^{15}$ and the Asymptomatic Carotid Atherosclerosis Study (ACAS). ${ }^{16}$ A study comparing angiographic surface morphology with detailed histology has concluded that ulceration detected by XRA was associated with plaque rupture, intraplaque hemorrhage, and overall plaque instability. ${ }^{17}$ An example of plaque ulceration on XRA is shown in Fig 2.

However, there are several limitations to the extensive use of XRA, especially in the carotid territory. XRA involves ionizing radiation. It is a high-cost and time-consuming procedure and requires adequate bed rest after the investigation. The invasive nature of this procedure increases the risk of creating emboli, resulting in subsequent cerebrovascular events. ${ }^{16,18,19}$ In an article based on ACAS, there was a $1.2 \%$ risk of persisting neurologic deficits or death following XRA, while the surgical risk was only $1.5 \% .{ }^{16}$ Another article based on NASCET showed that a $0.7 \%$ risk of persistent neurologic deficits or death was associated with the angiography. ${ }^{19} \mathrm{XRA}$ is not safe in patients with coagulopathies and bleeding disorders. The accuracy of XRA in detecting ulceration also depends on the degree of stenosis. ${ }^{20}$ Finally, the rates of false-positives and false-negatives of XRA were high in identifying ulcerations. ${ }^{21}$ Two possible reasons for its low accuracy in detecting ulceration are that it is operator-dependent and DSA generally acquires only a limited number of projections. These issues result in failures to detect ulceration ${ }^{21,22}$ and a tendency to underestimate stenosis. ${ }^{23}$
Based on the above-mentioned reasons, there has been a trend to replace XRA with alternative cost-effective, safe, and less time-consuming carotid imaging modalities, which are discussed below.

\section{Sonography}

Sonography was introduced as the first platform to visualize the in vivo human vessel and atherosclerosis. ${ }^{24}$ It helps to classify the plaque texture as either homogeneous (uniform consistency) or heterogeneous (nonuniform consistency). ${ }^{25}$ Homogeneous plaques present with a uniform echo intensity and show a regular, smooth surface, while heterogeneous plaques show a nonuniform pattern with mixed echo intensities and usually have an irregular/ulcerated surface. ${ }^{25}$ The plaque surface can be defined as smooth and regular, mildly irregular, or ulcerated in the case of a variation in height between 0.4 and 2 $\mathrm{mm}$ on the contour of the plaque. ${ }^{26}$ An example of ulceration in Doppler sonography is shown in Fig $3 A$. However, it is difficult to detect plaque ulceration by sonography due to various limitations. First, the overall accuracy of using B-mode sonography against criterion standard techniques (DSA or histopathology) is not high (sensitivity and specificity ranges from $39 \%$ to $89 \%$ and $72 \%$ to $87 \%$, respectively). ${ }^{27-29}$ Several studies have noted that its accuracy decreases with the increasing degree of stenosis, ${ }^{30,31}$ and it has even failed to detect ulceration in high-grade stenosis. ${ }^{29}$ The application of color-flow Doppler-assisted duplex imaging, which combines the B-mode and blood-flow velocity information, ${ }^{32}$ also shows limitations in providing adequate information to identify plaque ulcerations. ${ }^{31,33}$ Second, the intrareader reproducibility of both Bmode and Doppler sonography is low ( $\kappa$ ranges from 0.11 to $\left.0.89^{31,34-36}\right)$, which is not sufficient for reliable diagnosis. Third, the criteria for carotid ulceration diagnosis are very subjective and may vary from reader to reader or center to center; this variation makes its use difficult for multicenter trials. $^{37}$

These limitations are mostly due to the native imaging principle. 2D sonography can only obtain a $2 \mathrm{D}$ cut plane of the carotid area; this could introduce operator error when the sonography probe is not parallel to the vessel axis or the orientation of the ulceration. ${ }^{38}$ Also, the presence of calcifica- 
Table 2: Summary of details in each imaging modality

\begin{tabular}{|c|c|c|c|}
\hline $\begin{array}{l}\text { Imaging Modality/ } \\
\text { Subtype }\end{array}$ & Spatial Resolution & Advantages & Disadvantages \\
\hline XRA & $<0.5 \mathrm{~mm}$ & $\begin{array}{l}\text { High spatial and temporal resolution } \\
\text { Traditionally criterion standard }\end{array}$ & $\begin{array}{l}\text { Expensive } \\
\text { Postprocedural cerebrovascular events } \\
\text { Low accuracy in high-stenosis plaque } \\
\text { High false-positive/-negative rates } \\
\text { Limited number of projections } \\
\text { Depends on operator }\end{array}$ \\
\hline \multicolumn{4}{|l|}{ US } \\
\hline $\begin{array}{l}\text { 2D US } \\
\text { 3D US } \\
\text { Doppler US } \\
\text { CEUS }\end{array}$ & $\begin{array}{l}\text { In-plane: }<1 \mathrm{~mm} \\
\text { Through-plane: }<2 \mathrm{~mm}\end{array}$ & $\begin{array}{l}\text { Low cost, fast, and safe } \\
\text { Doppler US could quantify the flow } \\
\text { velocity in the ulcer }\end{array}$ & $\begin{array}{l}\text { B-mode and Doppler: low intrareader reproducibility } \\
\text { 2D methods depend on operator } \\
\text { B-mode: low-accuracy for high-stenosis plaque } \\
\text { Doppler: limited accuracy } \\
\text { Artifacts due to calcification }\end{array}$ \\
\hline \multicolumn{4}{|l|}{ CTA } \\
\hline $\begin{array}{l}\text { Single-source } \\
\text { Dual-source }\end{array}$ & $\begin{array}{l}\text { In-plane: }<1 \mathrm{~mm} \\
\text { Through-plane: } 1-2 \mathrm{~mm}\end{array}$ & $\begin{array}{l}\text { Fast } \\
\text { Good sensitivity and specificity }\end{array}$ & $\begin{array}{l}\text { Single-source: limited accuracy due to calcification } \\
\text { lonizing radiation } \\
\text { Contrast agents not suitable for patients with poor } \\
\text { renal function }\end{array}$ \\
\hline \multicolumn{4}{|l|}{ MRI } \\
\hline $\begin{array}{l}\text { NCE-MRI } \\
\text { CE-MRI } \\
\text { BB MRI }\end{array}$ & $0.6-2 \mathrm{~mm}$ & $\begin{array}{l}\text { NEC-MRI and BB MRI: no need for } \\
\text { contrast agents } \\
\text { No artifacts from calcification } \\
\text { BB MRI allows plaque component } \\
\text { identification }\end{array}$ & $\begin{array}{l}\text { Expensive } \\
\text { Motion artifacts due to long scan times } \\
\text { TOF: low accuracy due to imaging principle } \\
\text { Not suitable for patients with contraindications } \\
\text { CE-MRA not suitable for patients with severe renal } \\
\text { impairment }\end{array}$ \\
\hline
\end{tabular}

Note:-NCE-MRI indicates non-contrast-enhanced MRI; BB MRI, black-blood MRI.

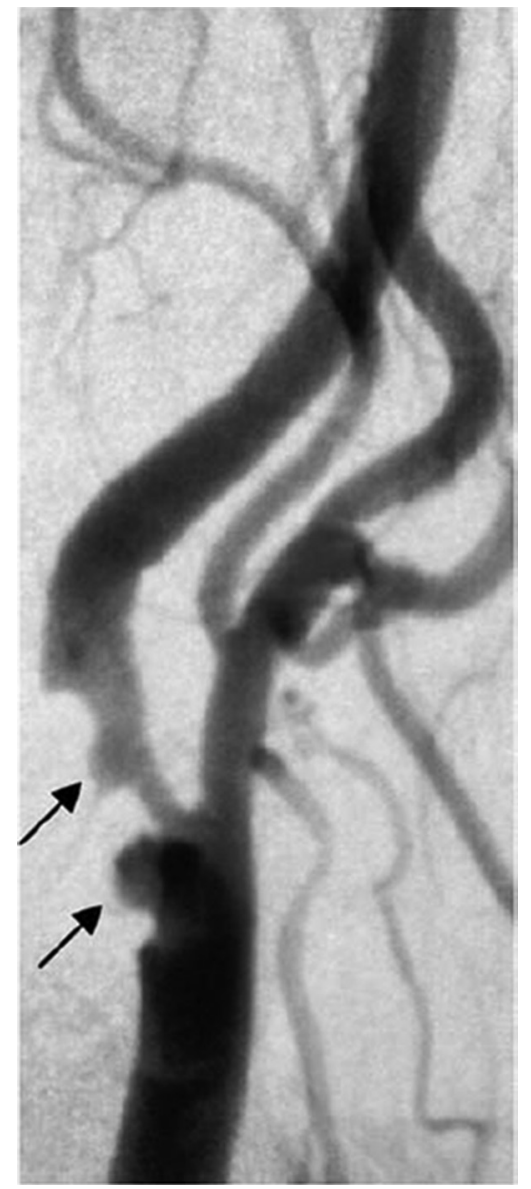

FIG 2. DSA image of 2 large ulcerations (arrows) of a right internal carotid artery. Reprinted with permission from Gillard et al. ${ }^{13}$ Copyright Cambridge University Press 2007. tion reflects the acoustic wave, which can obscure ulceration. ${ }^{38}$ An example of artifacts due to calcification is shown in Fig $3 B .^{39}$

The use of microbubble contrast agents has been shown to improve accuracy. A direct comparison of contrast-enhanced ultrasound (CEUS) and color Doppler ultrasound (CDUS) observed that CEUS has superior sensitivity and diagnostic accuracy over CDUS in detecting ulceration. ${ }^{40}$ Within the same study, CEUS detected more ulceration than CTA, especially small ulcerations, attributed to the higher spatial and temporal resolution achieved in CEUS. ${ }^{40}$ Further CEUS studies will be required to verify the improved accuracy of this technique. The safety of using CEUS should also be considered, including toxicity, microembolism, and inertial cavitation caused by the microbubbles. ${ }^{41}$

The recent development of $3 \mathrm{D}$ sonography has demonstrated superior ability in detecting ulceration compared with conventional 2D sonography (Fig 4). ${ }^{36,42} 3 \mathrm{D}$ sonographic images can be obtained by using dedicated $3 \mathrm{D}$ probes or by using $2 \mathrm{D}$ sonographic probes with the help of positioning sensors and postreconstruction algorithms to combine $2 \mathrm{D}$ sections into a $3 \mathrm{D}$ volume. ${ }^{43,44}$ This process improves image quality, provides more information about plaque morphology and echomorphology, and has been used to noninvasively quantify plaque stenosis ${ }^{45}$ and volume $e^{46,47}$ and examine the regression and progression of plaque ulceration. ${ }^{42}$ By comparing $3 \mathrm{D}$ and $2 \mathrm{D}$ sonography in 142 patients, Heliopoulos et $\mathrm{al}^{36}$ showed that 3D methods depicted more ulcerations than the 2D methods ( $15 \%$ versus $8 \%$ of plaques) and also had higher interobserver reproducibility $(\kappa=0.973$, standard error $=0.027$, versus $\kappa=0.885$, standard error $=0.055)$. However, this methodology is still under development and requires further 

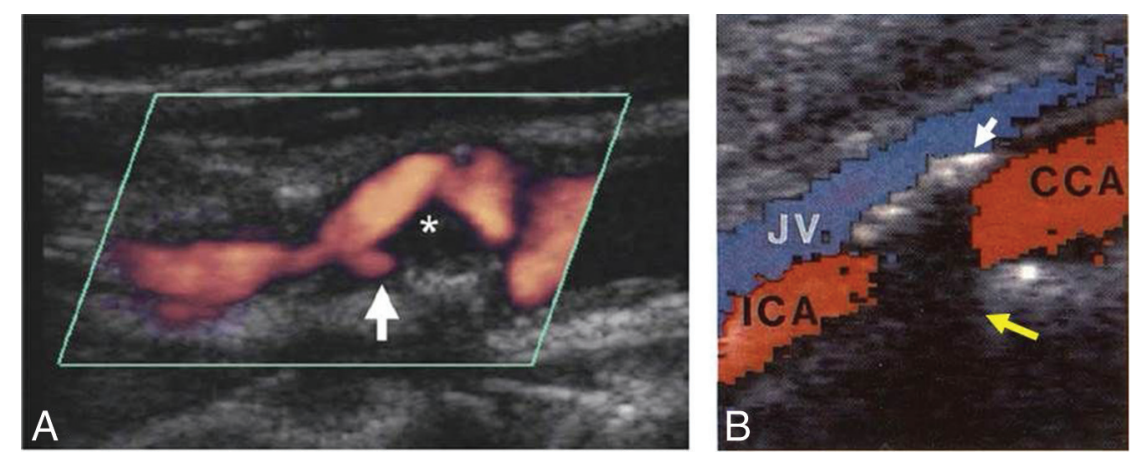

FIG 3. A, Doppler sonography shows an internal carotid artery plaque ulceration (white arrow) The asterisk shows weakly echogenic plaque material, presumably lipid. Reprinted with permission from Gillard et al. ${ }^{13}$ Copyright Cambridge University Press 2007. B, The calcification in the anterior vessel wall (white arrow) shadows the color Doppler signal and opposite wall structures (yellow arrow). JV indicates jugular vein; CCA, common carotid artery. Adapted from Steinke et al. $^{39}$
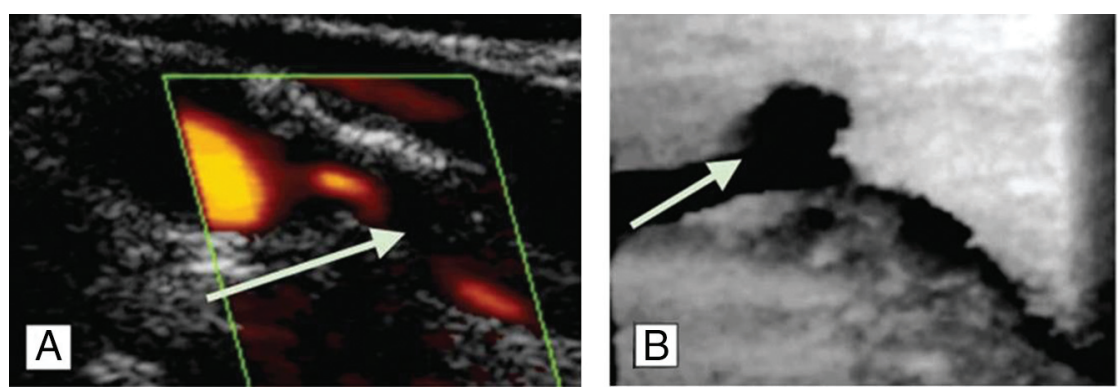

FIG 4. A, 2D sonography depicts a smooth plaque, arrow shows the stenosis. B, 3D sonography shows an ulceration of the same plaque in another plane, arrow shows an ulcer at site of shear stress. The figure is adapted with permission from Heliopoulos et al. ${ }^{36}$

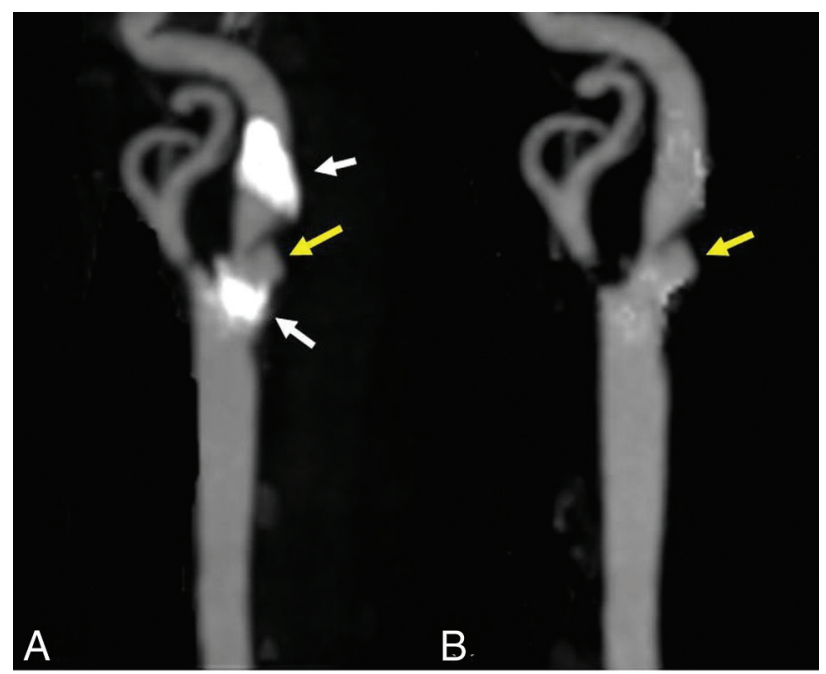

FIG 5. A, An ulceration (yellow arrow) in a heavily calcified (white arrows) plaque. $B$, The ulcer is clearer with the calcification removed by dual-energy CTA.

validation against accepted criterion standard techniques such as DSA and histopathology.

\section{CTA}

Studies with CTA have demonstrated that plaque ulceration is closely associated with increased lipid volume, ${ }^{48,49}$ an increased degree of stenosis, ${ }^{38}$ plaque volume, and decreased calcification proportions. ${ }^{49}$ Surgical observations have shown good correlation, with CTA having a high sensitivity (94\%) and specificity $(99 \%)$ to detect plaque ulceration. $^{50}$ Compared with sonography, CTA showed higher sensitivity and specificity to detect ulceration. ${ }^{38}$

In comparison with DSA, CTA has fewer associated complications, ${ }^{38}$ while its accuracy in the determination of ulceration still needs more research for validation. One major limitation of CTA in detecting ulceration is the appearance of plaque calcification. ${ }^{51}$

The recent development of dualsource CT, which uses $2 \mathrm{x}$-ray energies simultaneously to separate high-density calcification and the contrast-enhanced lumen, has shown advantages for evaluating densely calcified carotid stenosis and could be more accurate. ${ }^{52,53}$ Figure 5 shows that the morphology of ulcerations cannot be visualized clearly by conventional CTA due to calcification, while dual-source CTA software could remove the calcification from the image, making the ulcer clearer.

Like XRA, a drawback of CTA is the use of ionizing radiation. In imaging the neck vessels, the radiation dose of CTA is equivalent to or higher compared with that in DSA. ${ }^{54,55}$ Also, the use of contrast media may be contraindicated in some patients with poor renal function. ${ }^{56}$

\section{MR Imaging}

Noncontrast-Enhanced MRA. The most common method for MRA is time-of-flight, which relies on the high MR imaging signal from the moving blood within the vessel lumen to create vascular contrast. ${ }^{57}$ Both $2 \mathrm{D}$ (ie, multi-slice ${ }^{58}$ ) and $3 \mathrm{D}$ (ie, volumetric ${ }^{57,59}$ ) TOF have been used for carotid artery imaging. One of the biggest advantages of MRA over DSA and US is that the images can be reformatted into any orientation after the acquisition.

However, one of the well-known limitations of TOF-MRA is that signal saturation and dephasing of the signal could lead to a signal loss from focal areas of complex flow. ${ }^{60}$ The stenosis measurement accuracy of TOF is dependent on the wash-in efficiency of unsaturated spins within the imaging section/slab. For large ulcerations, the hemodynamic patterns of blood flow are complicated. ${ }^{61}$ Ulceration detection could therefore be limited if the saturated spins are not replaced by fresh unsaturated blood flow. Also, the orientation of the imaging section/slab is important. TOF techniques are limited to the flow orthogonal or at a certain angle to the imaging sections/slabs. The signal from flowing blood parallel to the imaging sections/slabs can become saturated. ${ }^{59}$ In addition, the ulceration orientation, location, and shape could also influence the accuracy of measurements with TOF-MRA. ${ }^{61}$ Spatial resolution would be 
another limitation of TOF-MRA, especially for very small ulcers. ${ }^{59}$ In addition, patient motion during relatively long acquisition times is another limitation. ${ }^{59}$

In recent years, other non-contrast-enhanced MRA techniques have emerged claiming to overcome some of the limitations of TOF-MRA. Arterial spin-labeling-based methods subtract images where fresh flowing blood has been magnetically "labeled" from images without labeling. Such methods have demonstrated the ability to image arteries of the head and neck without signal from static background. ${ }^{62,63}$ In particular, a hybrid of pseudocontinuous and pulsed arterial spin-labeling with a fast low-angle shot readout has shown similar results in detecting carotid luminal irregularity with contrast-enhanced MRA (CE-MRA) and overcomes some of the limitations of TOF-MRA (Fig 6). ${ }^{63}$ The inversion recovery-based methods ${ }^{64}$

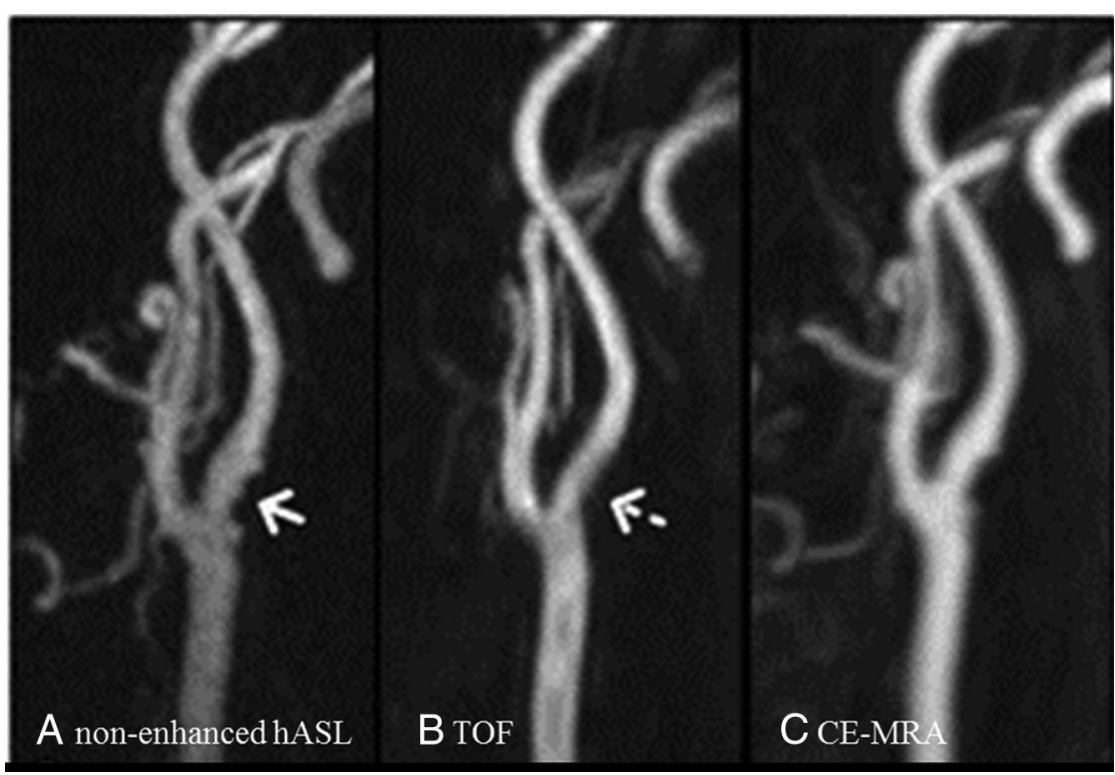

FIG 6. Luminal irregularity in the internal carotid artery is demonstrated on both a nonenhanced hybrid of pseudocontinuous and pulsed arterial spin-labeling (arrow, $A$ ) and CE-MRA (C) images, but it is not seen on the 3D TOF image (dashed arrow, B). hASL indicates hybrid of pseudocontinuous and pulsed ASL. The figure is reproduced with permission from Koktzoglou et al. ${ }^{63}$ and the quiescent interval low-angle shot method ${ }^{65}$ use inplane saturation pulses to suppress the background signal, allowing only the nonsaturated inflowing blood to be imaged. Blood-suppression-based methods use the subtraction of images with and without blood-suppression preparation pulses and have also shown good images of arteries and veins. ${ }^{66} \mathrm{Be}-$ cause these methods have only recently been developed, more studies are necessary to validate their accuracy in detecting plaque ulceration.

Contrast-Enhanced MRA. CE-MRA is an MR imaging technique for vascular imaging that exploits the use of an intravenously administered paramagnetic contrast agent (ie, a chelate of gadolinium) to shorten the T1 relaxation time of the blood, providing excellent contrast with the background tissues. Because the images are no longer dependent on the inflow of the blood, CE-MRA produces high-quality images in a short timeframe and may reduce some of the drawbacks associated with TOF-MRA. In 1 study, the prevalence of plaque ulceration was $86 \%$ in a symptomatic patient cohort compared with $36 \%$ in an asymptomatic patient group, indicating that CE-MRA could be used for detecting ulceration. ${ }^{67} \mathrm{CE}-\mathrm{MRA}$ has also been shown to detect more ulcers than TOFMRA. ${ }^{61}$ Figure $7 A$ shows an internal carotid artery with several ulcerations demonstrated by CE-MRA; however, all were missed by TOF-MRA (Fig 7B). In addition, CE-MRA has the advantage of depicting ulceration in calcified plaques, which is one of the limitations of standard CTA (Fig 7C). The images were processed by using a dedicated workstation (Advantage Windows 4.6; GE Healthcare, Milwaukee, Wisconsin).

Although CE-MRA shows high accuracy in detecting plaque ulceration, it is

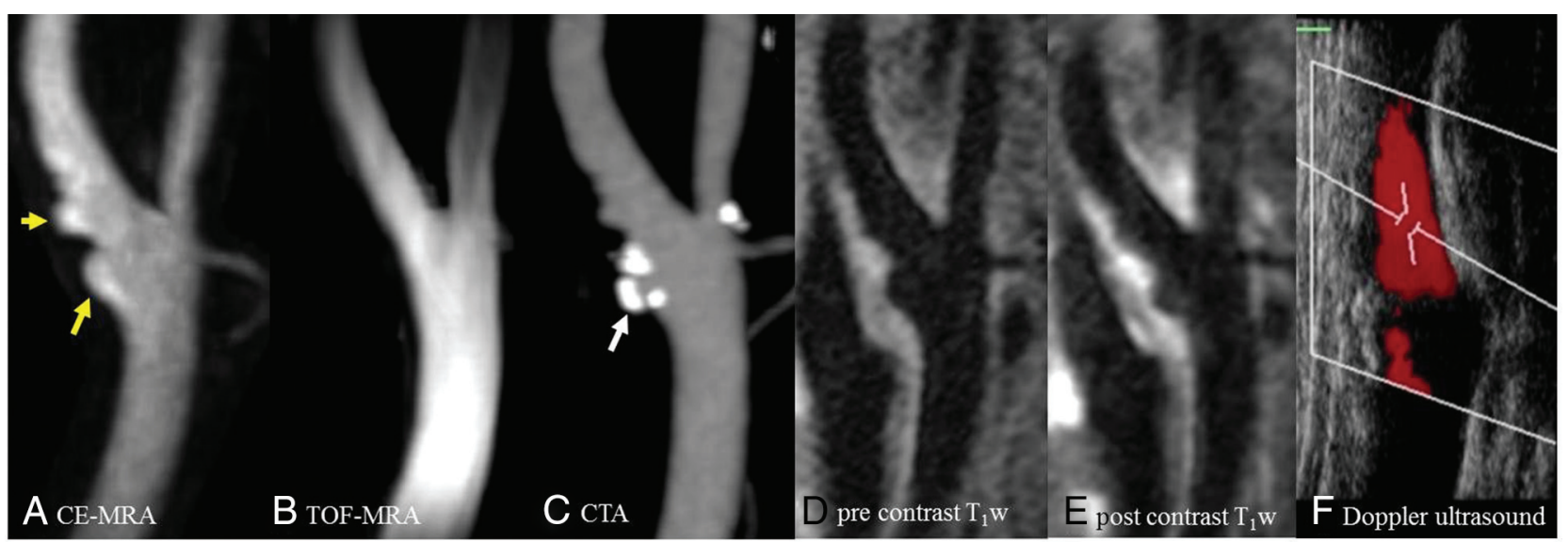

FIG 7. High-resolution MR imaging, CTA, and sonography of the left carotid artery of a 77-year-old man. Ulcerations (yellow arrow) are shown clearly on CE-MRA $(A)$ and pre- and postcontrast black-blood Tl-weighted ( $D$ and $E$ ) images; however, they were missed on TOF-MRA ( $B)$. The calcification on CTA (white arrow, $C$ ) causes difficulty when observing the ulceration. Doppler sonography $(F)$ shows no ulceration in the internal carotid artery. 
still a relatively expensive examination. MR imaging is not suitable for patients with contraindications such as implanted devices. In addition, the use of gadolinium-based contrast agents may be contraindicated in patients with severe renal impairment (eg, glomerular filtration rate $<30$ ), which may limit its wider application.

Blood-Suppressed MR Morphologic Imaging. High-resolution standard MR images are widely used for carotid morphologic imaging; however, the signal from flowing blood in the lumen makes it difficult to identify the vessel wall. Blood suppression is usually achieved through a signal-preparation scheme applied before the imaging sequence. The most commonly used schemes include double or quadruple inversion recovery, ${ }^{68,69}$ motion-sensitive driven equilibrium, ${ }^{70}$ and delay alternating with nutation for tailored excitation (DANTE). ${ }^{71}$ Multicontrast cross-sectional MR imaging with blood could also be used for ulceration detection. ${ }^{72,73}$ Figure $7 D,-E$ shows an example of carotid ulceration in DANTE-prepared pre- and postcontrast T1-weighted images.

\section{DISCUSSION}

Carotid ulceration is now considered a major hallmark in determining the vulnerability of atherosclerotic plaque because it indicates a previous plaque rupture and is a strong predictor of subsequent events. The identification of plaque ulceration may assist in the appropriate management of patients at risk of future ischemic events. We have reviewed the literature regarding the various radiologic techniques used to demonstrate plaque ulceration.

A direct comparison of the sensitivity and specificity of different imaging modalities is difficult because the definition of plaque ulceration varies in different studies. Pathologically, ulceration is defined as an erosion of the single cell-layer intima by microscopic examination ${ }^{74-76}$ or surface defects more than a certain value (such as $560 \mu \mathrm{m}$ or $1 \mathrm{~mm}$ in diameter and depth) in gross photography. ${ }^{12,28,29,77}$ In some studies with DSA, ${ }^{17} \mathrm{CTA},{ }^{49,78}$ and MRA, ${ }^{67,79}$ a general definition "the extended lumen into plaque" has been used. In some of the CTA studies, a more specific definition has been described, such as the intimal defect must be larger than $1 \mathrm{~mm}$ in width ${ }^{38,48,50}$ or $2 \mathrm{~mm}$ in depth. ${ }^{80}$

Sonography is limited by its accuracy and reproducibility, especially when the lesion is calcified. The recent development of $3 \mathrm{D}$ US and the use of CEUS may help improve the detection of carotid ulceration.

CTA is relatively safe compared with XRA and much faster and cheaper than MR imaging. However, as with XRA, ionization must be considered when using CTA. Optimization of the scanning protocol and the use of new reconstruction techniques ${ }^{81}$ can help reduce the radiation dose. The application of dual-source CTA may also help to improve the sensitivity and accuracy in detecting ulceration within calcified plaques.

The advantage of MR imaging is that morphologic and functional features of carotid plaque can be obtained within a single examination. These features could help provide a comprehensive assessment of plaque vulnerability. Non-contrast-enhanced MRA techniques have shown comparable efficiency with CE-MRA for detecting ulceration and could be used in patients with contraindications to contrast agents. By improving the resolution and optimizing the acquisition sequence, non-contrast-enhanced MRA techniques may identify smaller ulcerations missed by current MR imaging methods.

\section{REFERENCES}

1. World Health Organization. Cardiovascular Diseases (CVDs): Fact Sheet No. 317. 2011. Geneva: World Health Organization Google Scholar; 2011

2. Kistler JP, Furie KL. Carotid endarterectomy revisited. N Engl J Med 2000;342:1743-45 CrossRef Medline

3. Eliasziw M, Streifler JY, Fox AJ, et al. Significance of plaque ulceration in symptomatic patients with high-grade carotid stenosis: North American Symptomatic Carotid Endarterectomy Trial. Stroke 1994;25:304-08 CrossRef Medline

4. Handa N, Matsumoto M, Maeda $\mathrm{H}$, et al. Ischemic stroke events and carotid atherosclerosis: results of the Osaka follow-up study for ultrasonographic assessment of carotid atherosclerosis (the OSACA Study). Stroke 1995;26:1781-86 CrossRef Medline

5. Rothwell P, Villagra R, Gibson R, et al. Evidence of a chronic systemic cause of instability of atherosclerotic plaques. Lancet 2000; 355:19-24 CrossRef Medline

6. Rothwell PM, Gibson R, Warlow C. Interrelation between plaque surface morphology and degree of stenosis on carotid angiograms and the risk of ischemic stroke in patients with symptomatic carotid stenosis: on behalf of the European Carotid Surgery Trialists' Collaborative Group. Stroke 2000;31:615-21 CrossRef Medline

7. Prabhakaran S, Rundek T, Ramas R, et al. Carotid plaque surface irregularity predicts ischemic stroke: the northern Manhattan study. Stroke 2006;37:2696-701 CrossRef Medline

8. Rothwell PM, Mehta Z, Howard SC, et al. Treating individuals 3: from subgroups to individuals - general principles and the example of carotid endarterectomy. Lancet 2005;365:256-65 CrossRef Medline

9. Sadat U, Teng Z, Young V, et al. Association between biomechanical structural stresses of atherosclerotic carotid plaques and subsequent ischaemic cerebrovascular events-a longitudinal in vivo magnetic resonance imaging-based finite element study. Eur J Vasc Endovasc Surg 2010;40:485-91 CrossRef Medline

10. Miskolczi L, Guterman LR, Flaherty JD, et al. Depiction of carotid plaque ulceration and other plaque-related disorders by intravascular sonography: a flow chamber study. AJNR Am J Neuroradiol 1996;17:1881-90 Medline

11. Stary HC, Chandler AB, Dinsmore RE, et al. A definition of advanced types of atherosclerotic lesions and a histological classification of atherosclerosis: a report from the Committee on Vascular Lesions of the Council on Arteriosclerosis, American Heart Association. Circulation 1995;92:1355-74 CrossRef Medline

12. Sitzer M, Müller W, Siebler M, et al. Plaque ulceration and lumen thrombus are the main sources of cerebral microemboli in highgrade internal carotid artery stenosis. Stroke 1995;26:1231-33 CrossRef Medline

13. Gillard J, Graves M, Hatsukami T, et al. Carotid Disease: The Role of Imaging in Diagnosis and Management. Cambridge: Cambridge University Press; 2007:133

14. North American Symptomatic Carotid Endarterectomy Trial Collaborators. Beneficial effect of carotid endarterectomy in symptomatic patients with high-grade carotid stenosis. N Engl J Med 1991;325: 445-53 CrossRef Medline

15. Randomised trial of endarterectomy for recently symptomatic carotid stenosis: final results of the MRC European Carotid Surgery Trial (ECST). Lancet 1998;351:1379-87 CrossRef Medline

16. Endarterectomy for asymptomatic carotid artery stenosis: Executive Committee for the Asymptomatic Carotid Atherosclerosis Study. JAMA 1995;273:1421-28 Medline

17. Lovett J, Gallagher P, Hands L, et al. Histological correlates of carotid plaque surface morphology on lumen contrast imaging. Circulation 2004;110:2190-97 CrossRef Medline 
18. Hessel SJ, Adams DF, Abrams HL. Complications of angiography. Radiology 1981;138:273-81 CrossRef Medline

19. Barnett HJ, Meldrum HE, Eliasziw M; North American Symptomatic Carotid Endarterectomy Trial (NASCET) collaborators. The appropriate use of carotid endarterectomy. CMAJ 2002;166:1169-79 Medline

20. Edwards JH, Kricheff II, Riles T, et al. Angiographically undetected ulceration of the carotid bifurcation as a cause of embolic stroke. Radiology 1979;132:369-73 CrossRef Medline

21. Streifler JY, Eliasziw M, Fox AJ, et al. Angiographic detection of carotid plaque ulceration: comparison with surgical observations in a multicenter study - North American Symptomatic Carotid Endarterectomy Trial. Stroke 1994;25:1130-32 CrossRef Medline

22. Gandhi D. Computed tomography and magnetic resonance angiography in cervicocranial vascular disease. J Neuroophthalmol 2004;24: 306-14 CrossRef Medline

23. Ho VB, Foo TK. Optimization of gadolinium-enhanced magnetic resonance angiography using an automated bolus-detection algorithm (MR SmartPrep): original investigation. Invest Radiol 1998; 33:515-23 CrossRef Medline

24. Barnes R, Bone G, Reinertson J, et al. Noninvasive ultrasonic carotid angiography: prospective validation by contrast arteriography. Surgery 1976;80:328-35 Medline

25. Reilly LM, Lusby RJ, Hughes L, et al. Carotid plaque histology using real-time ultrasonography: clinical and therapeutic implications. Am J Surg 1983;146:188-93 CrossRef Medline

26. Dósa E, Hirschberg K, Apor A, et al. Echolucent or predominantly echolucent femoral plaques predict early restenosis after eversion carotid endarterectomy. J Vasc Surg 2010;51:345-50 CrossRef Medline

27. O'Donnell TF, Erdoes L, Mackey WC, et al. Correlation of B-mode ultrasound imaging and arteriography with pathologic findings at carotid endarterectomy. Arch Surg 1985;120:443-49 CrossRef Medline

28. O'Leary D, Holen J, Ricotta J, et al. Carotid bifurcation disease: prediction of ulceration with B-mode US. Radiology 1987;162:523-25 CrossRef Medline

29. Comerota AJ, Katz ML, White JV, et al. The preoperative diagnosis of the ulcerated carotid atheroma. J Vasc Surg 1990;11:505-10 Medline

30. Hennerici M, Baezner H, Daffertshofer M. Ultrasound and arterial wall disease. Cerebrovasc Dis 2004;17:19-33 Medline

31. Sitzer M, Müller W, Rademacher J, et al. Color-flow Doppler-assisted duplex imaging fails to detect ulceration in high-grade internal carotid artery stenosis. J Vasc Surg 1996;23:461-65 CrossRef Medline

32. Mitchell DG. Color Doppler imaging: principles, limitations, and artifacts. Radiology 1990;177:1-10 CrossRef Medline

33. De Bray J, Baud J, Dauzat M. Consensus concerning the morphology and the risk of carotid plaques. Cerebrovasc Dis 1997;7:289-96 CrossRef

34. Anderson DC, Loewenson R, Yock D, et al. B-mode, real-time carotid ultrasonic imaging: correlation with angiography. Arch Neurol 1983;40:484-88 CrossRef Medline

35. O'Leary D, Bryan F, Goodison M, et al. Measurement variability of carotid atherosclerosis: real-time (B-mode) ultrasonography and angiography. Stroke 1987;18:1011-17 CrossRef Medline

36. Heliopoulos J, Vadikolias K, Piperidou C, et al. Detection of carotid artery plaque ulceration using 3-dimensional ultrasound. J Neuroimaging 2011;21:126-31 CrossRef Medline

37. Geroulakos G, Hobson R, Nicolaides A. Ultrasonographic carotid plaque morphology in predicting stroke risk. Br J Surg 1996;83: 582-87 CrossRef Medline

38. Saba L, Caddeo G, Sanfilippo R, et al. CT and ultrasound in the study of ulcerated carotid plaque compared with surgical results: potentialities and advantages of multidetector row CT angiography. AJNR Am J Neuroradiol 2007;28:1061-66 CrossRef Medline

39. Steinke W, Kloetzsch C, Hennerici M. Carotid artery disease as- sessed by color Doppler flow imaging: correlation with standard Doppler sonography and angiography. AJNR Am J Neuroradiol 1990;11:259-66 Medline

40. ten Kate GL, van Dijk AC, van den Oord SC, et al. Usefulness of contrast-enhanced ultrasound for detection of carotid plaque ulceration in patients with symptomatic carotid atherosclerosis. $\mathrm{Am} \mathrm{J}$ Cardiol 2013;112:292-98 CrossRef Medline

41. Stride E, Saffari N. Microbubble ultrasound contrast agents: a review. Proc Inst Mech Eng H 2003;217:429-47 CrossRef Medline

42. Schminke U, Motsch L, Hilker L, et al. Three-dimensional ultrasound observation of carotid artery plaque ulceration. Stroke 2000; 31:1651-55 CrossRef Medline

43. Fenster A, Downey DB, Cardinal HN. Three-dimensional ultrasound imaging. Phys Med Boil 2001;46:R67 CrossRef Medline

44. Solberg OV, Lindseth F, Torp H, et al. Freehand 3D ultrasound reconstruction algorithms: a review. Ultrasound Med Boil 2007;33: 991-1009 CrossRef Medline

45. Yao J, van Sambeek MR, Dall'Agata A, et al. Three-dimensional ultrasound study of carotid arteries before and after endarterectomy: analysis of stenotic lesions and surgical impact on the vessel. Stroke 1998;29:2026-31 CrossRef Medline

46. Griewing B, Schminke U, Morgenstern C, et al. Three-dimensional ultrasound angiography (power mode) for the quantification of carotid artery atherosclerosis. J Neuroimaging 1997;7:40-45 CrossRef Medline

47. Palombo C, Kozakova M, Morizzo C, et al. Ultrafast three-dimensional ultrasound application to carotid artery imaging. Stroke 1998;29:1631-37 CrossRef Medline

48. Saba L, Sanfilippo R, Sannia S, et al. Association between carotid artery plaque volume, composition, and ulceration: a retrospective assessment with MDCT. AJR Am J Roentgenol 2012;199:151-56 CrossRef Medline

49. Homburg PJ, Rozie S, van Gils MJ, et al. Association between carotid artery plaque ulceration and plaque composition evaluated with multidetector CT angiography. Stroke 2011;42:367-72 CrossRef Medline

50. Saba L, Caddeo G, Sanfilippo R, et al. Efficacy and sensitivity of axial scans and different reconstruction methods in the study of the ulcerated carotid plaque using multidetector-row CT angiography: comparison with surgical results. AJNR Am J Neuroradiol 2007;28: 716-23 Medline

51. Link J, Brossmann J, Grabener M, et al. Spiral CT angiography and selective digital subtraction angiography of internal carotid artery stenosis. AJNR Am J Neuroradiol 1996;17:89-94 Medline

52. Korn A, Bender B, Thomas C, et al. Dual energy CTA of the carotid bifurcation: advantage of plaque subtraction for assessment of grade of the stenosis and morphology. Eur J Radiol 2011;80:e120-25 CrossRef Medline

53. Vlahos I, Chung R, Nair A, et al. Dual-energy CT: vascular applications. AJR Am J Roentgenol 2012;199:S87-97 CrossRef Medline

54. Klingebiel R, Kentenich M, Bauknecht H-C, et al. Comparative evaluation of 64-slice CT angiography and digital subtraction angiography in assessing the cervicocranial vasculature. Vasc Health Risk Manag 2008;4:901-07 Medline

55. Manninen AL, Isokangas JM, Karttunen A, et al. A comparison of radiation exposure between diagnostic CTA and DSA examinations of cerebral and cervicocerebral vessels. AJNR Am J Neuroradiol 2012;33:2038-42 CrossRef Medline

56. Hasebroock KM, Serkova NJ. Toxicity of MRI and CT contrast agents. Expert Opin Drug Metab Toxicol 2009;5:403-16 CrossRef Medline

57. Laub GA, Kaiser WA. MR angiography with gradient motion refocusing. J Comput Assist Tomogr 1988;12:377-82 CrossRef Medline

58. Gullberg GT, Wehrli FW, Shimakawa A, et al. MR vascular imaging with a fast gradient refocusing pulse sequence and reformatted images from transaxial sections. Radiology 1987;165:241-46 CrossRef Medline

59. Anderson C, Saloner D, Lee R, et al. Assessment of carotid artery 
stenosis by MR angiography: comparison with $\mathrm{x}$-ray angiography and color-coded Doppler ultrasound. AJNR Am J Neuroradiol 1992; 13:989-1003; discussion 1005-08 Medline

60. Yucel EK, Anderson CM, Edelman RR, et al. AHA scientific statement: magnetic resonance angiography update on applications for extracranial arteries. Circulation 1999;100:2284-301 CrossRef Medline

61. Etesami M, Hoi Y, Steinman D, et al. Comparison of carotid plaque ulcer detection using contrast-enhanced and time-of-flight MRA techniques. AJNR Am J Neuroradiol 2013;34:177-84 CrossRef Medline

62. Raoult H, Gauvrit JY, Schmitt P, et al. Non-ECG-gated unenhanced MRA of the carotids: optimization and clinical feasibility. Eur Radiol 2013;23:3020-28 CrossRef Medline

63. Koktzoglou I, Walker MT, Meyer JR, et al. Nonenhanced hybridized arterial spin labeled magnetic resonance angiography of the extracranial carotid arteries using a fast low angle shot readout at 3 Tesla. J Cardiovasc Magn Reson 2016;18:18 CrossRef Medline

64. Takei N, Miyoshi M, Kabasawa H. Noncontrast MR angiography for supraaortic arteries using inflow enhanced inversion recovery fast spin echo imaging. J Magn Reson Imaging 2012;35:957-62 CrossRef Medline

65. Koktzoglou I, Murphy IG, Giri S, et al. Quiescent interval low angle shot magnetic resonance angiography of the extracranial carotid arteries. Magn Reson Med 2016;75:2072-77 CrossRef Medline

66. Priest AN, Graves MJ, Lomas DJ. Non-contrast-enhanced vascular magnetic resonance imaging using flow-dependent preparation with subtraction. Magn Reson Med 2012;67:628-37 CrossRef Medline

67. Demarco J, Ota $\mathrm{H}$, Underhill $\mathrm{H}$, et al. MR carotid plaque imaging and contrast-enhanced MR angiography identifies lesions associated with recent ipsilateral thromboembolic symptoms: an in vivo study at 3T. AJNR Am J Neuroradiol 2010;31:1395-402 CrossRef Medline

68. Edelman RR, Chien D, Kim D. Fast selective black blood MR imaging. Radiology 1991;181:655-60 CrossRef Medline

69. Yarnykh VL, Yuan C. T1-insensitive flow suppression using quadruple inversion-recovery. Magn Reson Med 2002;48:899-905 CrossRef Medline

70. Wang J, Yarnykh VL, Hatsukami T, et al. Improved suppression of plaque-mimicking artifacts in black-blood carotid atherosclerosis imaging using a multislice motion-sensitized driven-equilibrium (MSDE) turbo spin-echo (TSE) sequence. Magn Reson Med 2007;58: 973-81 CrossRef Medline

71. Li L, Miller KL, Jezzard P. DANTE-prepared pulse trains: a novel approach to motion-sensitized and motion-suppressed quantitative magnetic resonance imaging. Magn Reson Med 2012;68:1423-38 CrossRef Medline

72. Chu B, Yuan C, Takaya N, et al. Images in cardiovascular medicine: serial high-spatial-resolution, multisequence magnetic resonance imaging studies identify fibrous cap rupture and penetrating ulcer into carotid atherosclerotic plaque. Circulation 2006;113:e660-61 CrossRef Medline

73. Chu B, Ferguson MS, Underhill $\mathrm{H}$, et al. Images in cardiovascular medicine: detection of carotid atherosclerotic plaque ulceration, calcification, and thrombosis by multicontrast weighted magnetic resonance imaging. Circulation 2005;112:e3-4 CrossRef Medline
74. Ackerman RH, Candia MR. Assessment of carotid artery stenosis by MR angiography. AJNR Am J Neuroradiol 1992;13:1005-08

75. Smith RR, Russell WF, Percy ML. Ultrastructure of carotid plaques. Surg Neurol 1980;14:145-53 Medline

76. Hertzer NR, Beven EG, Benjamin SP. Ultramicroscopic ulcerations and thrombi of the carotid bifurcation. Arch Surg 1977;112:13941402 CrossRef Medline

77. Fisher M, Martin A, Cosgrove M, et al. The NASCET-ACAS plaque project: North American Symptomatic Carotid Endarterectomy Trial-Asymptomatic Carotid Atherosclerosis Study. Stroke 1993; 24:I24-25; discussion I31-32 Medline

78. Berg M, Zhang Z, Ikonen A, et al. Multi-detector row CT angiography in the assessment of carotid artery disease in symptomatic patients: comparison with rotational angiography and digital subtraction angiography. AJNR Am J Neuroradiol 2005;26:1022-34 Medline

79. Saouaf R, Grassi C, Hartnell G, et al. Complete MR angiography and Doppler ultrasound as the sole imaging modalities prior to carotid endarterectomy. Clin Radiol 1998;53:579-86 CrossRef Medline

80. Wintermark M, Jawadi SS, Rapp JH, et al. High-resolution CT imaging of carotid artery atherosclerotic plaques. AJNR Am J Neuroradiol 2008;29:875-82 CrossRef Medline

81. Silva AC, Lawder HJ, Hara A, et al. Innovations in CT dose reduction strategy: application of the adaptive statistical iterative reconstruction algorithm. AJR Am J Roentgenol 2010;194:191-99 CrossRef Medline

82. Yao JS, Francfort J, Flinn WR, et al. Sonic characterization of carotid artery plaque and its surgical significance. In: Arterial Surgery: New Diagnostic and Operative Techniques. Orlando: Grune \& Stratton; 1988:161-70

83. Cumming MJ, Morrow IM. Carotid artery stenosis: a prospective comparison of CT angiography and conventional angiography. $A J R$ Am J Roentgenol 1994;163:517-23 CrossRef Medline

84. Patel MR, Kuntz KM, Klufas RA, et al. Preoperative assessment of the carotid bifurcation: can magnetic resonance angiography and duplex ultrasonography replace contrast arteriography? Stroke 1995;26:1753-58 CrossRef Medline

85. Kagawa R, Moritake K, Shima T, et al. Validity of B-mode ultrasonographic findings in patients undergoing carotid endarterectomy in comparison with angiographic and clinicopathologic features. Stroke 1996;27:700-05 CrossRef Medline

86. Randoux B, Marro B, Koskas F, et al. Carotid artery stenosis: prospective comparison of CT, three-dimensional gadolinium-enhanced MR, and conventional angiography. Radiology 2001;220: 179-85 CrossRef Medline

87. Berg M, Manninen H, Räsänen $\mathrm{H}$, et al. CT angiography in the assessment of carotid artery atherosclerosis. Acta Radiol 2002;43: 116-24 Medline

88. Alvarez-Linera J, Benito-León J, Escribano J, et al. Prospective evaluation of carotid artery stenosis: elliptic centric contrast-enhanced MR angiography and spiral CT angiography compared with digital subtraction angiography. AJNR Am J Neuroradiol 2003;24:1012-19 Medline

89. Lv P, Lin J, Guo D, et al. Detection of carotid artery stenosis: a comparison between 2 unenhanced MRAs and dual-source CTA. AJNR Am J Neuroradiol 2014;35:2360-65 CrossRef Medline 